\title{
Influence of ischemia/reperfusion and modulation of PI3K/Akt kinase pathway on matrix metalloproteinase- 2 in rat hearts
}

\author{
Anna Špániková1,2*, Monika Ivanová ${ }^{1 *}$, Jana Matejíková1, Táňa Ravingerová ${ }^{1}$ \\ and Miroslav Barančík ${ }^{1}$ \\ ${ }^{1}$ Institute for Heart Research, Slovak Academy of Sciences, Centre of Excellence for Cardiovascular Research SAS, Bratislava, \\ Slovakia; E-mail: Miroslav.Barancik@savba.sk \\ ${ }^{2}$ Institute of Molecular Physiology and Genetics, Centre of Excellence for Cardiovascular Research SAS, Bratislava, \\ Slovakia
}

\begin{abstract}
Matrix metalloproteinases (MMPs) are enzymes that play an important role in degradation and remodeling of extracellular matrix and MMP-2 has been also shown as a primary mediator of the acute mechanical dysfunction of the heart immediately after ischemia/reperfusion (I/R). The aims of the study were to investigate the influence of I/R on MMP-2 and to study the effects of wortmannin on modulation of MMP-2 activities after cycle of short I/R procedures (ischemic preconditioning, IP). Wortmannin is a specific inhibitor of PI3K/Akt kinase pathway activation of which was found to play a role in infarct size limiting mechanisms in the rat heart. In the study isolated Langendorff-perfused rat hearts subjected to protocols of prolonged (test) I/R and/or IP were used. Wortmannin was infused before and during the reperfusion phase of IP. The levels and activation of proteins were determined by immunoblot assay. The MMP-2 activities were measured by zymography. We found that ischemia induced time-dependent activation of tissue pro-MMP-2. Strong activation occurred after $15 \mathrm{~min}$ ischemia, during prolonged ischemia and following reperfusion the activities of this form of MMP-2 declined. The specific activities of both 72 and $63 \mathrm{kDa}$ forms of MMP-2 were increased in perfusates collected during reperfusion after $30 \mathrm{~min}$ ischemia and these activities peaked in the first minute of reperfusion. Cycle of short ischemia and reperfusion that led to increased cardiac tolerance against prolonged I/R reduced $72 \mathrm{kDa}$ MMP- 2 activities and induced also an activation of Akt kinase. The application of wortmannin was connected with inhibition of IP-mediated Akt kinase activation. Moreover, the actions of wortmannin were linked with modulation of MMP-2 activities. Our results suggest that MMP-2 may be involved in the responses of rat hearts to ischemia and point to possible relationship between Akt kinase and modulation of MMP-2 activities in rat hearts.
\end{abstract}

Key words: Matrix metalloproteinases — Heart — Ischemia — Akt kinase

\section{Introduction}

The exposure of myocardium to episodes of short ischemia followed by reperfusion leads to increased resistance of the heart against subsequent potentially lethal long-term

\footnotetext{
* both authors contributed equally to the study

Correspondence to: Miroslav Barančík, Institute for Heart Research, Slovak Academy of Sciences, Dúbravská cesta 9, P.O. Box 104, 84005 Bratislava, Slovakia

E-mail: Miroslav.Barancik@savba.sk
}

ischemia (Murry et al. 1986; Kloner and Jennings 2001). This phenomenon is known as ischemic preconditioning (IP) and several studies documented that cardioprotective effects similar to IP can also be induced pharmacologically by substances such as sildenafil, diazoxide (Kukreja et al. 2005; Šimončíková et al. 2007). Results of our recent study showed that the effects of diazoxide on reduction of myocardial injury after ischemia/reperfusion (I/R) in rat hearts were associated with an inhibition of matrix metalloproteinase- 2 activities (Šimončíková et al. 2007). Matrix metalloproteinases (MMPs) belong to the family 
of zinc-dependent endopeptidases which are synthesized as zymogens and are activated by proteolytic cleavage of an amino-terminal domain (Birkedal-Hansen 1995) or through conformational changes induced by oxidative stress (without a change in molecular weight) (Okamoto et al. 1997). These enzymes play an important role in degradation and remodeling of extracellular matrix under physiological and pathological conditions (Peterson et al. 2001). Moreover, it was found that MMP-2 activation also resulted in the degradation of specific proteins, including troponin I (Wang et al. 2002b), myosin light chain (Sawicki et al. 2005) and a-actinin (Sung et al. 2007). These data implicate some MMPs in modulation of acute physiologically relevant processes and for example MMP-2 has been shown as a primary mediator of the acute mechanical dysfunction of the heart immediately after ischemia and reperfusion (Cheung et al. 2000). Mechanisms that participate in injury induced by I/R involve also generation of oxidative stress in early phase of reperfusion after ischemia. The formed reactive oxygen species can trigger cascades of pathophysiological events, including activation of MMPs. This is supported also by findings that peroxynitrite, the reaction product of $\mathrm{NO}$ and superoxide, can activate proteolytic activity of proMMP-2 against several substrates including gelatin and troponin I (Viappiani et al. 2006, 2009). Peroxynitrite was also found to stimulate an acute release of MMP-2 from rat hearts during reperfusion (Cheung et al. 2000).

Several studies demonstrated that the expression and activation of MMPs is regulated through protein kinase cascades such as ERKs (Kurata et al. 2000) and PI3K/Akt (Bae et al. 2006). These signaling pathways were also found to play an important role in responses of heart to $I / R$ and in the mechanisms of heart adaptation to pathological situations (Strohm et al. 2000; Hausenloy et al. 2004; Strnisková et al. 2006). PI3K/Akt kinase cascade is implicated in processes of cell survival and metabolic control, and its activation was also found to play a role in infarct size limiting mechanisms in the rat heart (Ravingerová et al. 2007).

We have recently shown that positive changes in ischemic cardiac tolerance induced by pharmacological preconditioning (Šimončíková et al. 2007) and observed after development of chronic NO deficiency (Špániková et al. 2008) were connected with an inhibition in MMP-2 in the rat heart. This pointed to the role of this enzyme in responses of rat heart to I/R and in mechanisms of cardioprotection. Since Akt kinase activation was found to play an important role during ischemia and in cardioprotective adaptive responses in rat hearts, we suggested that the changes in MMP- 2 could also be related to this kinase pathway. Thus, the aim of our present study was to investigate the effects of I/R as well as procedure of IP on MMP-2. Furthermore, to elucidate the possible relation between MMP-2 and PI3K/Akt kinase pathway during IP the effects of specific inhibitor of PI3K/ Akt kinase pathway (wortmannin) on IP-induced changes in MMP-2 were determined.

\section{Materials and Methods}

\section{Experimental model}

In the study, adult male Wistar rats (250-280 g body weight) were used. All animals had free access to water and a standard laboratory diet. The study was performed in accordance with Guide for Care and Use of laboratory animals published by the US National Institutes of Health (NIH publication No. 85-23, revised 1996) and approved by the Animal Care and Use Committee of the Slovak Republic.

\section{Perfusion technique}

Rats were anesthetized (sodium pentobarbitone, $60 \mathrm{mg} / \mathrm{kg}$, i.p.) and given heparin (500 IU, i.p.). Hearts were rapidly excised, placed in ice-cold perfusion buffer, cannulated via the aorta and perfused in the Langendorff mode at a constant perfusion pressure of $70 \mathrm{mmHg}$ and at $37^{\circ} \mathrm{C}$. Perfusion solution was a modified Krebs-Henseleit buffer gassed with $95 \% \mathrm{O}_{2}$ and $5 \% \mathrm{CO}_{2}(\mathrm{pH} 7.4)$ containing (in mmol/l): $\mathrm{NaCl} 118.0 ; \mathrm{KCl} 3.2 ; \mathrm{MgSO}_{4} 1.2 ; \mathrm{NaHCO}_{3} 25.0$; $\mathrm{KH}_{2} \mathrm{PO}_{4}$ 1.18; $\mathrm{CaCl}_{2} 2.5$; glucose 7.0. Solution was filtered through a $5 \mu \mathrm{m}$ porosity filter (Millipore) to remove contaminants.

\section{Experimental protocols}

The Langendorff-perfused hearts were allowed to stabilize (20 min) before further interventions. In the protocol of test ischemia the hearts were exposed to $30 \mathrm{~min}$ global ischemia induced by stop of aortal inflow and $40 \mathrm{~min}$ reperfusion. Tissue samples from the left ventricle were collected at the beginning (before the test ischemia), at different time points of ischemia $(5,15,30 \mathrm{~min})$ and during the following reperfusion $(10,20 \mathrm{~min})$. All tissue samples were frozen in liquid nitrogen and stored at $-75^{\circ} \mathrm{C}$ until further analysis. Perfusates were collected after stabilization (before ischemia) and during reperfusion that followed the preceding ischemia. All samples were stored at $-75^{\circ} \mathrm{C}$ until further analysis.

The protocol of IP was evoked by one cycle of short $5 \mathrm{~min}$ ischemia and $5 \mathrm{~min}$ reperfusion. In drug studies, wortmannin $(100 \mathrm{nmol} / \mathrm{l})$ was applied $5 \mathrm{~min}$ before and during reperfusion phase of IP protocol. Tissue samples from the left ventricle were collected at the beginning (before the first 
short ischemia) and at the end of IP procedure. All tissue samples were frozen in liquid nitrogen and stored at $-75^{\circ} \mathrm{C}$ until further analysis.

\section{Preparation of protein fractions}

The tissue samples from left ventricle were wiped in liquid nitrogen, resuspended in ice-cold buffer A containing (in $\mathrm{mmol} / \mathrm{l}): 20$ Tris- $\mathrm{HCl}, 250$ sucrose, 1.0 EGTA, 1.0 dithiothreitol (DTT), 1.0 phenylmethylsulfonylfluoride (PMSF) and 0.5 sodium orthovanadate $(\mathrm{pH} 7.4)$ and homogenized with a Teflon glass homogenizer. The homogenates were centrifuged at $800 \times g$ for $5 \mathrm{~min}$ at $4^{\circ} \mathrm{C}$ and the supernatants after this centrifugation were centrifuged again at $16100 \times g$ for $30 \mathrm{~min}$. The postmitochondrial supernatants after this second centrifugation were used for further analysis. The protein concentrations were estimated by the method of Bradford (Bradford 1976).

\section{Preparation of perfusates}

To investigate the influence of ischemia on release of metalloproteinases from tissue into circulation, perfusates were collected before the onset of ischemia (at the end of stabilization) and at 1, 5, 10 and $20 \mathrm{~min}$ of reperfusion that followed the $30 \mathrm{~min}$ ischemia. The perfusates were dialysed overnight against redistilled water $\left(\right.$ at $\left.4^{\circ} \mathrm{C}\right)$. After dialysis, samples were freeze-dried, resuspended in $300 \mu \mathrm{l}$ of $20 \mathrm{mmol} / \mathrm{l}$ Tris- $\mathrm{HCl}$ (pH 7.40) and used for preparation of electrophoretic samples to gelatin zymography and Western blot analysis.

\section{Electrophoresis and immunochemical Western blot analysis}

Protein fractions containing equivalent amounts of ventricular proteins were separated by sodium dodecyl sulfate-polyacrylamide gel electrophoresis (SDS-PAGE). Total contents or activation of proteins were determined by Western blot analysis using specific antibodies. For Western blot assays, proteins after electrophoretic separation were transferred to nitrocellulose membrane. The quality of transfer was controlled by Ponceau $S$ staining of nitrocellulose membranes after transfer and protein loading by using glyceraldehyde3-phosphate dehydrogenase (GAPH) as a housekeeper. Specific anti-Akt kinase, anti-MMP-2, anti-GAPDH (all from Santa Cruz Biotechnology), anti-phospho-Akt kinase (from Cell Signaling Technology) antibodies were used for primary immunodetection. Peroxidase-labelled anti-rabbit immunoglobulin (Cell Signaling Technology) was used as the secondary antibody. Bound antibodies were detected by the enhanced chemiluminescence (ECL) detection method.
Measurement of MMP activities by gelatin zymography

The gelatinolytic activities of MMPs were determined by the modified method of Schonbeck et al. (1997). Laemmli buffer without 2-mercaptoethanol in proportion $1: 1$ was added to protein samples and non-heated samples were subjected to electrophoresis on $10 \%$ SDS-polyacrylamide gels co-polymerized with gelatin $(2 \mathrm{mg} / \mathrm{ml})$. After electrophoresis, gels were washed twice for $20 \mathrm{~min}$ each with $50 \mathrm{mmol} / \mathrm{l}$ Tris- $\mathrm{HCl}$ (pH 7.4), containing $2.5 \%$ Triton X-100, at $25^{\circ} \mathrm{C}$. After washing, the gels were incubated overnight at $37^{\circ} \mathrm{C}$ in substrate buffer containing $50 \mathrm{mmol} / \mathrm{l}$ Tris- $\mathrm{HCl}, 10 \mathrm{mmol} / \mathrm{l} \mathrm{CaCl} 2$ and $1.25 \%$ Triton $\mathrm{X}-100, \mathrm{pH}$ 7.4. After this incubation, the gels were stained with $1 \%$ Coomassie Brilliant Blue G-250, resolved in mixture of methanol : acetic acid : water $(4: 1: 5)$ for 2 hours at room temperature and then destained with $40 \%$ methanol and $10 \%$ acetic acid. Gelatinolytic activities of MMP-2 were detected as transparent bands against dark blue background.

\section{Statistical evaluation}

Quantification of protein levels was done using Phosphorimager Thyphoon (Amersham Biosciences). Data were expressed as means \pm S.E.M. Statistical significance of differences between the groups was analysed by the unpaired Student's $t$-test. Differences were considered significant at $p<0.05$.

\section{Results}

\section{Effect of $I / R$ on levels and activities of $M M P-2$}

Protein levels of tissue MMP-2 we determined using specific antibody that reacts with a $72 \mathrm{kDa}$ (pro-MMP-2) and $63 \mathrm{kDa}$ form of MMP-2. The results showed no significant differences in the levels of these MMP-2 forms between tissue of control hearts and hearts after ischemia and reperfusion (Fig. 1A). Activities of MMPs were analyzed by zymography using gelatin as a substrate. As a positive control for identification of $63 \mathrm{kDa}$ MMP-2 we used recombinant active MMP-2 (Calbiochem) and pro-MMP-2 was identified using fetal bovine serum containig predominantly activity of this $72 \mathrm{kDa}$ form of MMP-2. In tissue samples we detected predominantly enzymatic gelatinolytic activities of oxidatively activated $72 \mathrm{kDa}$ form of MMP-2 and we found activation of this form of enzyme induced by ischemia (Fig. 1B,D). Strong activation occurred after $15 \mathrm{~min}$ of ischemia, during prolonged $30 \mathrm{~min}$ ischemia and the following reperfusion the activation of this enzyme declined. For $63 \mathrm{kDa}$ (proteolytically activated) form of MMP-2, we did not observe intensive gelatinolytic bands and $\mathrm{I} / \mathrm{R}$ also did not induce an activation of this form of MMP-2. 
A

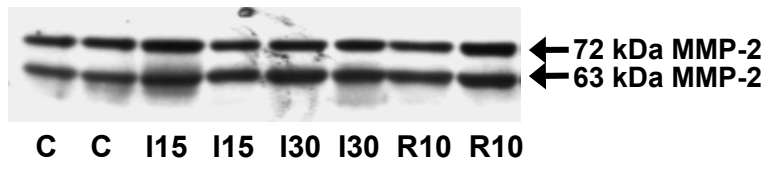

B

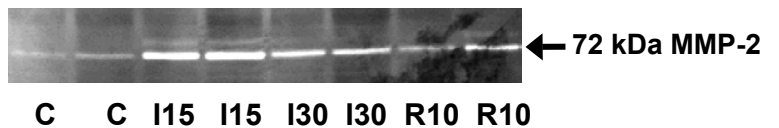

D

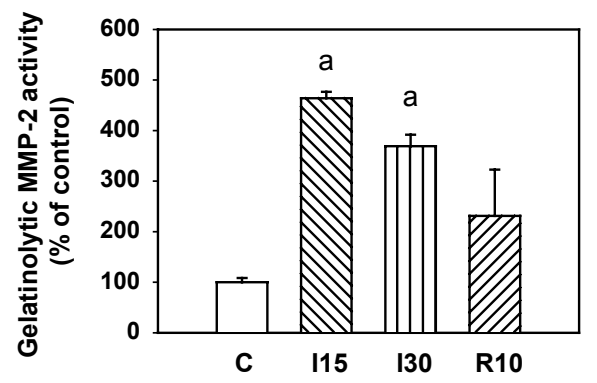

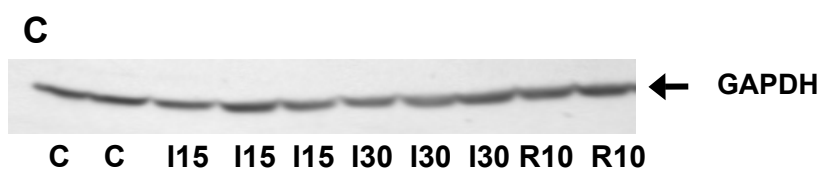

Figure 1. Effect of I/R on activities of tissue MMP-2. A. The record shows protein levels of MMP-2 determined using specific antibody that reacts with $72 \mathrm{kDa}$ (pro-MMP-2) and $63 \mathrm{kDa}$ form of MMP-2. The arrows on the right show the positions of these forms of MMP-2. B. The activities of MMP-2 in protein fractions isolated from the left ventricular tissue of rat hearts at the basal conditions (control - before ischemia) and during ischemia and reperfusion were analyzed by zymography in $10 \%$ polyacrylamide gels containing gelatin as a substrate. The arrow on the right shows the gelatinolytic activity of $72 \mathrm{kDa}$ MMP-2. C. The protein levels of GAPDH determined using specific antibody. C, control rat hearts (before ischemia); I15, 15 min ischemia; I30, 30 min ischemia; R10, 10 min reperfusion. D. Quantitative analysis of $72 \mathrm{kDa}$ MMP-2 activities. Data are expressed as a percentage of values for control tissue. Each bar represents mean \pm S.E.M., ${ }^{\mathrm{a}} p<0.05$ vs. control group.

\section{Effect of $I / R$ on release of MMP-2 into circulation}

The release of MMP-2 was analysed in perfusates which were sampled during reperfusion that followed 30 min lasting ischemia. Gelatin zymography of perfusates showed gelatinolytic activity corresponding to both 72 - and $63-\mathrm{kDa}$ forms of MMP-2. After 1 min of reperfusion both 72 and $63 \mathrm{kDa}$ MMP-2 activities were significantly increased in comparison to perfusates obtained before ischemia (Fig. 2A,C,D). During prolonged reperfusion the activities of both forms of MMP-2 declined. Increased MMP-2 activities after 1 min of reperfusion were accompanied by significant increases in protein levels as measured by Western blot analysis (Fig. 2B).

\section{Effect of $I / R$ on $M M P-2$}

To explore the influence of short cycle of ischemia and reperfusion (IP procedure) on the protein levels and activities of MMP-2, we performed Western blot analysis and zymography of heart ventricular tissue samples taken before (control) and after IP procedure. The results obtained using antibody that reacts with $72 \mathrm{kDa}$ and $63 \mathrm{kDa}$ forms of MMP- 2 showed no significant differences in the levels of these MMP-2 forms between tissue of control and preconditioned hearts (Fig. 3A). On the other hand, in preconditioned hearts exposed to cycle of $5 \mathrm{~min}$ ischemia and $5 \mathrm{~min}$ reperfusion we found significant reduction of gelatinolytic activity of $72 \mathrm{kDa}$ MMP-2 (Fig. 3B,C).

\section{Effect of PI3K/Akt kinase pathway inhibitor on IP-mediated changes in Akt kinase}

Analysis with the antibody specific for Akt kinase revealed no differences in the levels of Akt kinase between the control and preconditioned rat hearts (Fig. 4A). Also the application of wortmannin did not influence the Akt kinase levels (Fig. 4A). On the other hand, detection with a phosphospecific antibody (Ser473) showed increased phosphorylation (activation) of Akt kinase in the preconditioned hearts as compared with non-preconditioned controls (Fig. 4B,C). Application of wortmannin reversed the IP-mediated effects on Akt kinase and we found significant inhibition of the IP-mediated Akt kinase phosphorylation (activation) (Fig. 4B,C).

Effect of PI3K/Akt kinase pathway inhibitor on IP-mediated changes in $M M P-2$

Analysis of MMP-2 activities by zymography in gels containing gelatin as a substrate showed that IP reduced 
A

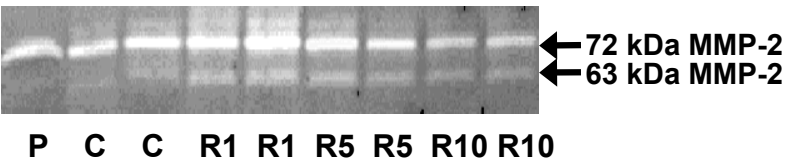

B

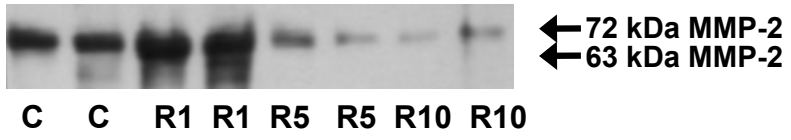

C

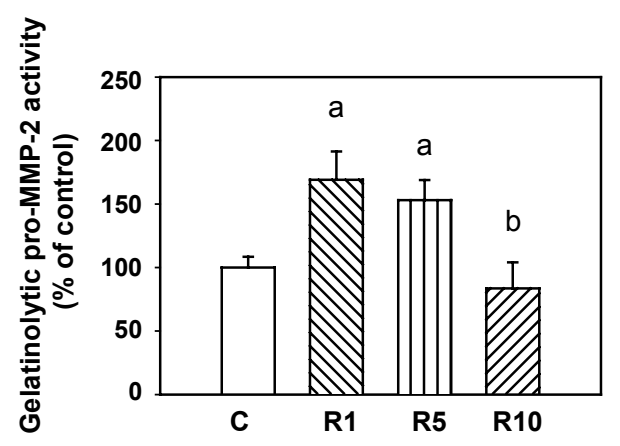

D

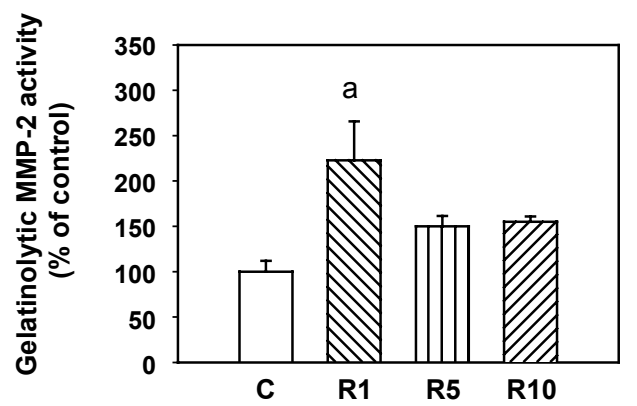

Figure 2. Effect of I/R on release of MMP-2 into circulation. A. The release of MMP was analysed in perfusates that were sampled during reperfusion following $30 \mathrm{~min}$ lasting ischemia. Activities of MMPs were analyzed by zymography in 10\% polyacrylamide gels containing gelatin as a substrate. The arrows on the right show the gelatinolytic activity of $72 \mathrm{kDa}$ (pro-MMP-2) and $63 \mathrm{kDa}$ form of MMP-2. B. Protein levels of MMP-2 in perfusates obtained at the basal (control) conditions (before ischemia) and during reperfusion (after ischemia). The MMP-2 levels were determined using specific antibody that reacts with $72 \mathrm{kDa}$ (pro-MMP-2) and $63 \mathrm{kDa}$ form of MMP-2. The arrows on the right show the positions of these forms of MMP-2. C. Quantitative analysis of activities of $72 \mathrm{kDa}$ form of MMP-2 (pro-MMP-2). Data are expressed as a percentage of values for MMP-2 activity in control perfusates. Each bar represents mean \pm S.E.M., ${ }^{\mathrm{a}} p<0.05 v s$. control group, ${ }^{\mathrm{b}} p<0.05 \mathrm{vs}$. R5 group. D. Quantitative analysis of activities of $63 \mathrm{kDa}$ form of MMP-2. Data are expressed as a percentage of values for MMP-2 activity in control perfusates. Each bar represents mean \pm S.E.M., ${ }^{a} p<0.05 v s$. control group. C, perfusates after stabilization, before ischemia; R1, 1 min reperfusion; R5, 5 min reperfusion; R10, 10 min reperfusion.

the activities of $72 \mathrm{kDa}$ form MMP-2 and application of wortmannin (Fig. 5A,B) reversed the IP-mediated effects on activities of this form of MMP-2. Analysis with the specific antibody showed that these changes in MMP-2 activities were not associated with modulation of protein levels (Fig. 5C).

\section{Discussion}

In the present study, we showed that cycle of short ischemia and reperfusion that lead to increased cardiac tolerance against prolonged I/R induced an activation of Akt kinase and reduced MMP-2 activities. The results also show that application of inhibitor of PI3K/Akt kinase pathway was connected with inhibition of IP-mediated Akt kinase activa- tion and the effects of wortmannin were also linked with modulation of MMP-2 activities. Furthermore, we have shown that ischemia induced time dependent activation of $72 \mathrm{kDa}$ form of tissue MMP-2 and immediately after start of reperfusion both 72 and $63 \mathrm{kDa}$ MMP-2 activities were significantly increased in heart perfusates. The present study also added evidence to possible relationship between Akt kinase and modulation of MMP-2 activities during IP.

MMPs are zinc-dependent endopeptidases that play an important role in degradation and remodeling of extracellular matrix under physiological and pathological conditions (Peterson et al. 2001). The findings that MMP-2 activation is involved in the degradation of proteins unrelated to extracellular matrix, such as troponin I, myosin light chain, a-actinin (Wang et al. 2002b; Sawicki et al. 2005; Sung et 
A

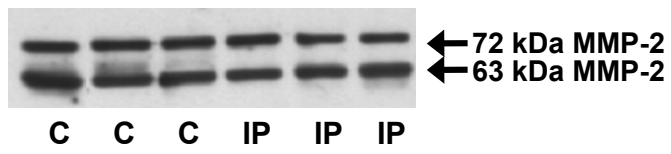

B

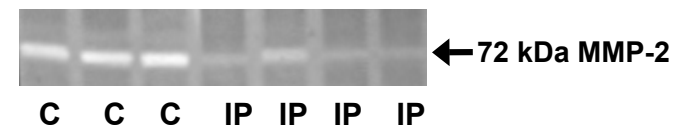

C

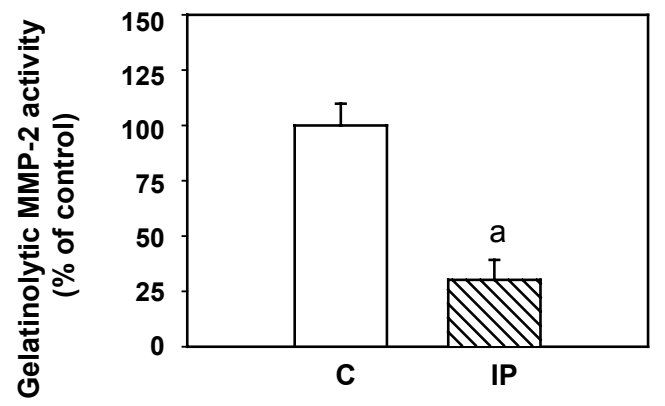

Figure 3. Effect of IP on MMP-2. A. The record shows protein levels of MMP-2 determined using specific antibody that reacts with $72 \mathrm{kDa}$ (pro-MMP-2) and $63 \mathrm{kDa}$ form of MMP-2. The arrows on the right show the positions of these forms of MMP-2. B. Record shows the gelatinolytic activity of MMP-2 in protein fractions isolated from the left ventricular tissue of control (C) and preconditioned (IP) rat hearts. The MMP-2 activities were analyzed by zymography in $10 \%$ polyacrylamide gels containing gelatin as a substrate. The arrow on the right shows the gelatinolytic activity of $72 \mathrm{kDa}$ MMP-2. C. Quantitative analysis of $72 \mathrm{kDa}$ MMP-2 activities. Data are expressed as a percentage of values for control tissue. Each bar represents mean \pm S.E.M., ${ }^{a} p<0.05 v s$. control group. C, control rat hearts (before ischemia); IP, preconditioned hearts exposed to one cycle of $5 \mathrm{~min}$ ischemia and 5 min reperfusion.

A

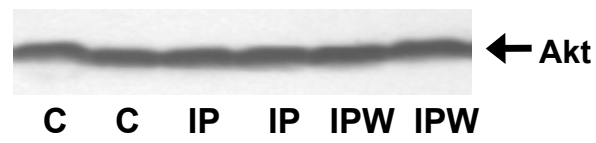

B

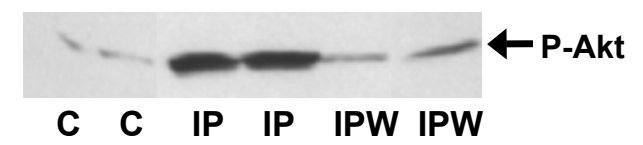

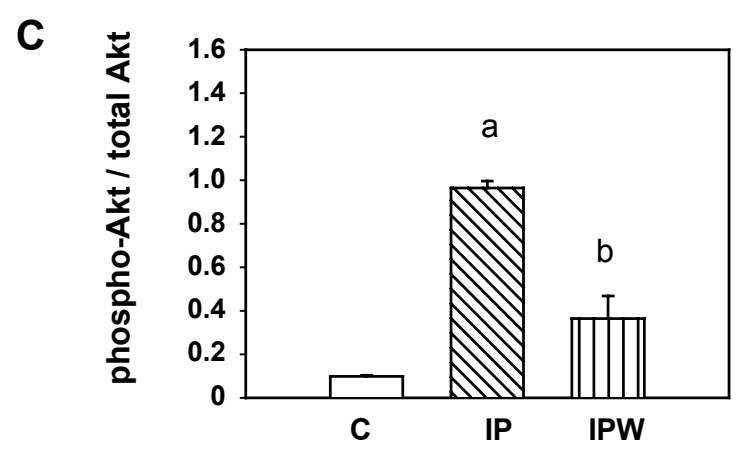

Figure 4. Effect of inhibitor of PI3K/Akt kinase pathway on IP-mediated changes in Akt kinase. A. Western blot record showing the influence of IP and wortmannin on protein levels of Akt kinase. Levels of this enzyme were determined using specific antibody. The arrow on the right shows the position of Akt kinase. B. The changes in specific phosphorylation of Akt kinase in protein fractions isolated from left ventricular tissue of control hearts (C), preconditioned hearts (IP) and hearts treated before and during IP with wortmanin (IPW). The Akt kinase activation was determined using phospho-specific antibody (Ser473). The arrow on the right shows the position of this activated enzyme. C. The quantification of Akt kinase phosphorylation. Data were obtained from Western blot records and are expressed as a ratio of content of phosphorylated Akt kinase to total Akt kinase. Each bar represents mean \pm S.E.M., ${ }^{\mathrm{a}} p<0.05 v s$. control group, ${ }^{\mathrm{b}} p<0.05$ vs. IP group. C, control rat hearts (before ischemia); IP, preconditioned hearts exposed to one cycle of 5 min ischemia and 5 min reperfusion; IPW, hearts treated before and during IP with wortmannin. 
A

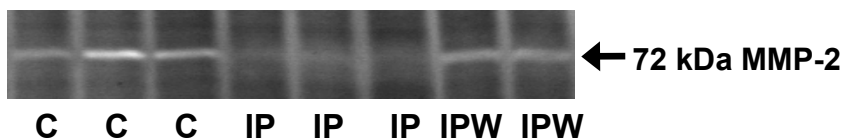

B

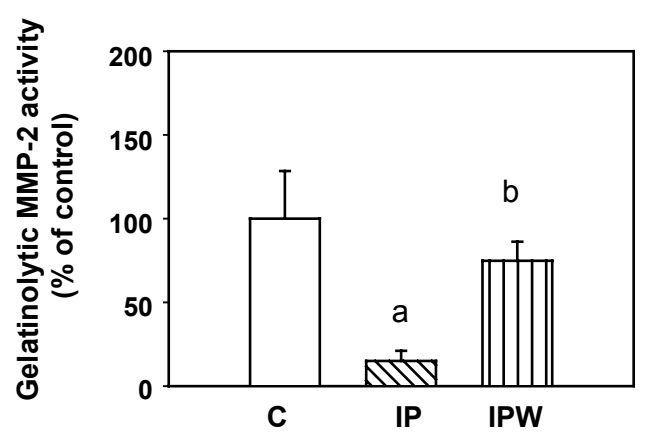

C

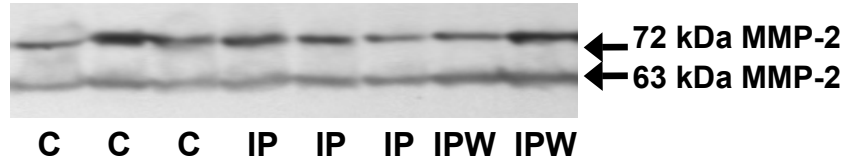

Figure 5. Effect of inhibitor of PI3K/Akt kinase pathway on IP-mediated changes in MMP-2. A. Record after gelatin zymography showing the influence of IP and wortmannin on activities of tissue MMP-2. The MMP-2 activities were analyzed by zymography in $10 \%$ polyacrylamide gels containing gelatin as a substrate. The arrow on the right shows the gelatinolytic activity of $72 \mathrm{kDa}$ MMP- 2 . B. Quantitative analysis of MMP-2 activities after IP and treatment with wortmannin. Data were obtained from zymograms and are expressed as a percentage of values for control tissue. Each bar represents mean \pm S.E.M., ${ }^{\mathrm{a}} p<0.05 v$ s. control group, ${ }^{\mathrm{b}} p<0.05$ vs. IP group. C. Influence of IP and wortmannin on protein levels of MMP-2. The levels of MMP-2 were determined using specific antibody. The arrows on the right show the positions of 72 and $63 \mathrm{kDa}$ forms of MMP-2. C, control rat hearts (before ischemia); IP, preconditioned hearts exposed to one cycle of $5 \mathrm{~min}$ ischemia and $5 \mathrm{~min}$ reperfusion; IPW, hearts treated before and during IP with wortmannin.

al. 2007), implicate this enzyme in a variety of acute physiologically relevant processes. The inhibition of MMP-2 after procedure of IP observed in our study might also suggest that modulation of activities of this enzyme can be involved in the mechanisms responsible for increased tolerance of preconditioned rat hearts against I/R injury. To the possible role of MMP-2 in cardioprotection produced by preconditioning point also the results of study of Lalu et al. (2002). In this was shown that preconditioning of rat hearts with three brief periods of no flow ischemia significantly decreased the activation and release of tissue MMP-2 into the perfusate after test I/R. Our results showed that tissue pro-MMP-2 activation is reduced already at the end of cycles of short ischemia and reperfusion, before the following test ischemia. Similar down-regulation of MMP-2 activities before start of test ischemia we found recently also after pharmacological preconditioning induced by diazoxide (Šimončíková et al. 2007). This suggests that important role in mechanisms of cardioprotection induced by these different forms of short-term adaptation procedures plays the observed reduction of MMP-2 activities at the beginning of test ischemia. Inhibition of MMP using inhibitors may provide benefits in the treatment of cardiac diseases through protecting cardiac myocytes and also by protecting the integrity of endothelium and possibly intracellular membranes (Fert-Bober et al. 2008). To the significant role of MMP-2 in processes associated with I/R point our data showing the time-dependent changes of MMP-2 activities during prolonged ischemia and release of the active enzyme into the effluent during the following reperfusion. Negative role of MMP-2 during ischemia was documented in studies showing that MMP-2 is a primary modulator of the acute mechanical dysfunction of the heart following ischemia and reperfusion and inhibition of its activity significantly improved cardiac function (Cheung et al. 2000; Wang et al. 2002a).

In heart tissue of left ventricle we identified the 72 and $63 \mathrm{kDa}$ forms of MMP-2 by Western blot analysis. 
The $72 \mathrm{kDa}$ form corresponds to pro-MMP-2 (zymogen) and $63 \mathrm{kDa}$ MMP-2 is active form of enzyme which is a product of proteolytic cleavage of pro-MMP-2. By zymography of tissue samples we detected mainly the gelatinolytic activity corresponding to molecular weights of $72 \mathrm{kDa}$ and despite the observed changes in gelatinolytic activity we did not observe changes in tissue protein content of this enzyme. The observed activity of $72 \mathrm{kDa}$ form corresponds to pro-MMP-2 activated through conformational changes induced by oxidative stress. It is suggested that powerful endogenous oxidant, such as peroxynitrite, can activate MMPs by reacting with a critical cysteine residue without loss of the propeptide (Okamoto et al. 2001). Thus, the changes in myocardial peroxynitrite biosynthesis may influence the MMP-2 activity without changes of pro-peptide or changes in expression. Ischemia and reperfusion are associated with generation of oxygen free radicals, including superoxide and peroxynitrite (Bolli and Marban 1999). It was also documented that the biosynthesis of peroxynitrite in the heart is greatly enhanced during the first minute of reperfusion after ischemia (Yasmin et al. 1997). We found that at the first minute of reperfusion peaked also the activities of pro-MMP-2 and $62 \mathrm{kDa}$ MMP- 2 that were released to the perfusates. These results indicate that formation of peroxynitrite can contribute to the pro-MMP-2 activation. In agreement with this are also the results of study where the reduction of endogenous peroxynitrite formation in the consequence of preconditioning has been observed (Csonka et al. 2001) and in our study observed inhibition of $72 \mathrm{kDa}$ MMP-2 at the end of IP procedure. Moreover, in recent study we observed that in consequence of NO synthases activities inhibition by L-NAME also MMP-2 activities are down-regulated (Špániková et al. 2008).

We found that procedure of IP induced in addition to observed inhibition of MMP-2 activities also an activation of Akt kinase. Similarly to our finding, also other study documented increased phosphorylation of Akt kinase during acute IP (Tong et al. 2000). Moreover, PI3K/Akt kinase pathway has been implicated in the mechanisms of various forms of cardioprotection (short-term and long-term), such as classical ischemic or hypoxic preconditioning and its delayed (second window) phase, as well as pharmacologically induced preconditioning (Hausenloy et al. 2004; Uchiyama et al. 2004; Ravingerová et al. 2007). The present study documented that application of wortmannin, inhibitor of PI3K/Akt kinase pathway, abolished the IP-induced changes in modulation of both Akt kinase and MMP-2 activities in rat hearts. Thus, the observed changes in MMP-2 during IP may be related to changes in activation of pro-survival PI3K/Akt kinase cascade. Some other studies demonstrated also a link between PI3K/Akt kinase pathway and regulation of MMPs expression and activation but in contrast to our data obtained after IP, the results showed that the induction of Akt kinase activation resulted in up-regulation of MMPs (Bae et al. 2006; Lee et al. 2007). Lee at al. (2007) found that high amount of glucose $(25 \mathrm{mmol} / \mathrm{l})$ induced enhanced production and zymographic activity of MMP-2 in adventitial fibroblasts prepared from the mice thoracic aorta. This MMP-2 production was attenuated by inhibition of PI3K/Akt pathway and the results showed that the effects of Akt kinase on MMP-2 were realized through enhanced activity of MMP-2 promoter and activation of gene transcription. Positive influence of PI3K/Akt kinase pathway on induction of MMP-2 expression was found also in gastric cancer cells (Bae et al. 2006). In contrast to results of these studies, despite the changes in gelatinolytic activity we did not observe changes in expression, production of MMP-2 and the effects of Akt kinase were not realized at the transcriptional level. Important is also fact that changes observed in our study (after IP) were realized in short time - within several minutes. On the other hand, Lee et al. (2007) documented the effects of PI3K/Akt pathway inhibition on MMP-2 after prolonged time (24 h). This suggests that the observed discrepancies in role of Akt kinase by MMP-2 regulation can be attributed to substantial differences in mode of action of Akt kinase at different time and experimental models.

In summary, we have demonstrated that prolonged $\mathrm{I} / \mathrm{R}$ induced activation of MMP-2. On the other hand, the procedure of IP resulted in inhibition of MMP-2 activities and this was associated with an activation of Akt kinase. Furthermore, the inhibition of Akt kinase resulted in reversal of IP-mediated inhibition of MMP-2 activities. The results indicate that MMP- 2 may be involved in the responses of rat hearts to ischemia and modulation of its activities by Akt kinase may occur during the procedure of IP.

Acknowledgements. Supported by VEGA SR grant No. 2/0205/09, 2/7169/27, 2/0173/08, APVV 51-027404.

\section{References}

Bae I. H., Park M. J., Yoon S. H., Kang S. W., Lee S. S., Choi K. M., Um H. D. (2006): Bcl-w promotes gastric cancer cell invasion by inducing matrix metalloproteinase- 2 expression via phosphoinositide 3-kinase, Akt, and Sp1. Cancer Res. 66, 4991-4995; doi:10.1158/0008-5472. CAN-05-4254

Birkedal-Hansen H. (1995): Proteolytic remodeling of extracellular matrix. Curr. Opin. Cell. Biol. 7, 728-735; doi:10.1016/ 0955-0674(95)80116-2

Bolli R., Marban E. (1999): Molecular and cellular mechanisms of myocardial stunning. Physiol. Rev. 79, 609-634

Bradford M. (1976): A rapid and sensitive method for the quantitation of microgram quanties of protein utilizing the principle of protein-dye-binding. Anal. Biochem. 72, 248-254; doi:10.1016/0003-2697(76)90527-3 
Hausenloy D. J., Mocanu M. M., Yellon D. M. (2004): Cross-talk between the survival kinases during early reperfusion: its contribution to ischemic preconditioning. Cardiovasc. Res. 63, 305-312; doi:10.1016/j.cardiores.2004.04.011

Cheung P. Y., Sawicki G., Wozniak M., Wang W., Radomski M. W., Schulz R. (2000): Matrix metalloproteinase- 2 contributes to ischemia-reperfusion injury in the heart. Circulation 101, 1833-1839

Csonka C., Csont T., Onody A., Ferdinandy P. (2001): Preconditioning decreases ischemia/reperfusion-induced peroxynitrite formation. Biochem. Biophys. Res. Commun. 285, 1217-1219; doi:10.1006/bbrc.2001.5308

Fert-Bober J., Leon H., Sawicka J., Basran R. S., Devon R. M., Schulz R., Sawicki G. (2008): Inhibiting matrix metalloproteinase- 2 reduces protein release into coronary effluent from isolated rat hearts during ischemia-reperfusion. Basic Res. Cardiol. 103, 431-443; doi:10.1007/s00395008-0727-y

Hausenloy D. J., Mocanu M. M., Yellon D. M. (2004): Cross-talk between the survival kinases during early reperfusion: its contribution to ischemic preconditioning. Cardiovasc. Res. 63, 305-312; doi:10.1016/j.cardiores.2004.04.011

Kloner R. A., Jennings R. B. (2001): Consequences of brief ischemia: stunning, preconditioning, and their clinical implications. Circulation 104, 2981-2989; doi:10.1161/ hc4801.100038

Kukreja R. C., Salloum F., Das A., Ockaili R., Yin C., Bremer Y. A., Fisher P. W., Wittkamp M., Hawkins J., Chou E., Kukreja A. K., Wang X., Marwaha V. R., Xi L. (2005): Pharmacological preconditioning with sildenafil: basic mechanisms and clinical implications. Vascul. Pharmacol. 42, 219-232; doi:10.1016/j.vph.2005.02.010

Kurata H., Thant A. A., Matsuo S., Senga T., Okazaki K., Hotta N., Hamaguchi M. (2000): Constitutive activation of MAP kinase kinase (MEK1) is critical and sufficient for the activation of MMP-2. Exp. Cell. Res. 254, 180-188; doi:10.1006/excr.1999.4738

Lalu M. M., Csonka C., Giricz Z., Csont T., Schulz R., Ferdinandy P. (2002): Preconditioning decreases ischemia/reperfusioninduced release and activation of matrix metalloproteinase-2. Biochem. Biophys. Res. Commun. 296, 937-941; doi:10.1016/S0006-291X(02)02019-3

Lee S. J., Bae S. S., Kim K. H., Lee W. S., Rhim B. Y., Hong K. W., Kim C. D. (2007): High glucose enhances MMP-2 production in adventitial fibroblasts via Akt1-dependent NF-кB pathway. FEBS Lett. 581, 4189-4194; doi:10.1016/ j.febslet.2007.07.058

Murry C. E., Jennings R. B., Reimer K. A. (1986): Preconditioning with ischemia: a delay of lethal cell injury in ischemic myocardium. Circulation 74, 1124-1136

Okamoto T., Akaike T., Nagano T., Miyajima S., Suga M., Ando M., Ichimori K., Maeda H. (1997): Activation of human neutrophil procollagenase by nitrogen dioxide and peroxynitrite: a novel mechanism for procollagenase activation involving nitric oxide. Arch. Biochem. Biophys. 342, 261-274; doi:10.1006/abbi.1997.0127

Okamoto T., Akaike T., Sawa T., Miyamoto Y., van der Vliet A., Maeda H. (2001): Activation of matrix metalloprotein- ases by peroxynitrite-induced protein S-glutathiolation via disulfide S-oxide formation. J. Biol. Chem. 276, 29596-29602; doi:10.1074/jbc.M102417200

Peterson J. T., Hallak H., Johnson L., Li H., O'Brien P. M., Sliskovic D. R., Bocan T. M., Coker M. L., Etoh T., Spinale F. G. (2001): Matrix metalloproteinase inhibition attenuates left ventricular remodeling and dysfunction in a rat model of progressive heart failure. Circulation 103, 2303-2309

Ravingerová T., Matejíková J., Neckář J., Andelová E., Kolář F. (2007): Differential role of PI3K/Akt pathway in the infarct size limitation and antiarrhythmic protection in the rat heart. Mol. Cell. Biochem. 297, 111-120; doi:10.1007/ s11010-006-9335-z

Sawicki G., Leon H., Sawicka J., Sariahmetoglu M., Schulze C. J., Scott P. G., Schulz R. (2005): Degradation of myosin light chain in isolated.rat hearts subjected to ischemia-reperfusion injury: a new intracellular target for matrix metalloproteinase-2. Circulation 112, 544-552; doi:10.1161/ CIRCULATIONAHA.104.531616

Schonbeck U., Mach F., Sukhova G. K., Murphy C., Bonnefoy J. Y., Fabunmi R. P., Libby P. (1997): Regulation of matrix metalloproteinase expression in human vascular smooth muscle cells by T lymphocytes. Circ. Res. 81, 448-454

Strnisková M., Ravingerová T., Neckár J., Koláŕ F., Pastoreková S., Barančík M. (2006): Changes in the expression and/or activation of regulatory proteins in rat hearts adapted to chronic hypoxia. Gen. Physiol. Biophys. 25, 25-41

Strohm C., Barančík M., Bruhl M. L., Kilian S. A., Schaper W. (2000): Inhibition of the ER-kinase cascade by PD98059 and UO126 counteracts ischemic preconditioning in pig myocardium. J. Cardiovasc. Pharmacol. 36, 218-229; doi:10.1097/00005344-200008000-00012

Sung M. M., Schulz C. G., Wang W., Sawicki G., Bautista-Lopez N. L., Schulz R. (2007): Matrix metalloproteinase-2 degrades the cytoskeletal protein a-actinin in peroxynitrite mediated myocardial injury. J. Mol. Cell. Cardiol. 43, 429-436; doi:10.1016/j.yjmcc.2007.07.055

Šimončíková P., Ravingerová T., Andelová E., Tribulová N., Barančík M. (2007): Changes in rat myocardium associated with modulation of ischemic tolerance by diazoxide. Gen. Physiol. Biophys. 26, 75-85

Špániková A., Šimončíková P., Ravingerová T., Pecháňová T., Barančík M. (2008): The effect of chronic nitric oxide synthases inhibition on regulatory proteins in rat hearts. Mol. Cell. Biochem. 312, 113-120; doi:10.1007/s11010008-9726-4

Tong H., Chen W., Steenberg C., Murphy E. (2000): Ischemic preconditioning activates phosphatidylinositol-3-kinase upstream of protein kinase C. Circ. Res. 87, 309-315

Uchiyama T., Engelman R. M., Maulik N., Das D. K. (2004): Role of Akt signaling in mitochondrial survival pathway triggered by hypoxic preconditioning. Circulation 109, 3042-3049; doi:10.1161/01.CIR.0000130647.29030.90

Viappiani S., Sawicki G., Crawford B., Leon H., Schulz R. (2006): Peroxynitrate modulates $72 \mathrm{kDa}$ matrix metalloproteinase- 2 activity through s-nitrosylation of critical cysteines. J. Mol. Cell. Cardiol. 40, 907; doi:10.1016/ j.yjmcc.2006.03.405 
Viappiani S., Nicolescu A. C., Holt A., Sawicki G., Crawford B. D., Leon H., van Mulligen T., Schulz R. (2009): Activation and modulation of $72 \mathrm{kDa}$ matrix metalloproteinase-2 by peroxynitrite and glutathione. Biochem. Pharmac. 77, 826-834; doi:10.1016/j.bcp.2008.11.004

Wang W., Sawicki G., Schulz R. (2002a): Peroxynitrite-induced myocardial injury is mediated through matrix metalloproteinase-2. Cardiovasc. Res. 53, 165-174; doi:10.1016/ S0008-6363(01)00445-X

Wang W., Schulze C. J., Suarez-Pinzon W. L., Dyck J. R., Sawicki G., Schulz R. (2002b): Intracellular action of matrix metal- loproteinase- 2 accounts for acute myocardial ischemia and reperfusion injury. Circulation 106, 1543-1549; doi:10.1161/01.CIR.0000028818.33488.7B

Yasmin W., Strynadka K. D., Schulz R. (1997): Generation of peroxynitrite contributes to ischemia-reperfusion injury in isolated rat hearts. Cardiovasc. Res. 33, 422- 432; doi:10.1016/S0008-6363(96)00254-4

Received: May 15, 2009

Final version accepted: September 9, 2009 